\title{
Paralemnolide A, an Unprecedented Bisnorsesquiterpene from the Taiwanese Soft Coral Paralemnalia thyrsoides
}

\section{Shang-Kwei Wang ${ }^{1,2}$, Yu-Sheng Lee ${ }^{3}$ and Chang-Yih Duh ${ }^{1,3, *}$}

1 Asia-Pacific Ocean Research Center, National Sun Yat-Sen University, Kaohsiung 804, Taiwan; E-Mail: skwang@cc.kmu.edu.tw

2 Department of Microbiology, Kaohsiung Medical University, Kaohsiung 807, Taiwan

3 Department of Marine Biotechnology and Resources, National Sun Yat-Sen University, Kaohsiung 804, Taiwan; E-Mail: m995020028@student.nsysu.edu.tw

* Author to whom correspondence should be addressed; E-Mail: yihduh@mail.nsysu.edu.tw; Tel.: +886-7-525-2000 (ext. 5036); Fax: +886-7-525-5020.

Received: 8 June 2012; in revised form: 26 June 2012 / Accepted: 11 July 2012 /

Published: 17 July 2012

\begin{abstract}
Paralemnolide A (1), possessing an unprecedented bisnorsesquiterpene skeleton, was isolated from the soft coral Paralemnalia thyrsoides. The structure of paralemnolide A was elucidated by extensive analysis of spectroscopic data. The anti-HCMV (human cytomegalovirus) activity of $\mathbf{1}$ and its cytotoxicity against selected cell lines were evaluated.
\end{abstract}

Keywords: Paralemnalia thyrsoides; paralemnolide A; cytotoxicity; anti-HCMV

\section{Introduction}

Soft corals of the genus Paralemnalia [1-8] have been found to be rich sources of sesquiterpenoids of nardosinane [1-3], neolemnane [3,4] and africanane-type [3] compounds, as well as norsesquiterpenoids of nornardosinane-type [3,5,6] compounds. As part of the continuing search for bioactive substances from marine invertebrates, we explored the secondary metabolites of the soft coral Paralemnalia thyrsoides (Ehrenberg, 1934) which was collected from Sansiantai, Taitong County, Taiwan (Figure 1). Chromatographic separation on the acetone extract of the soft coral $P$. thyrsoides resulted in the isolation of paralemnolide A (1), which possesses an unprecedented bisnorsesquiterpene skeleton (Figure 2). The anti-HCMV (human cytomegalovirus) activity of 1 and its cytotoxicity against P-388 (mouse lymphocytic leukemia), HT-29 (human colon adenocarcinoma), and A549 (human lung carcinoma) cancer cell lines were evaluated in vitro. 
Figure 1. Soft coral Paralemnalia thyrsoides.

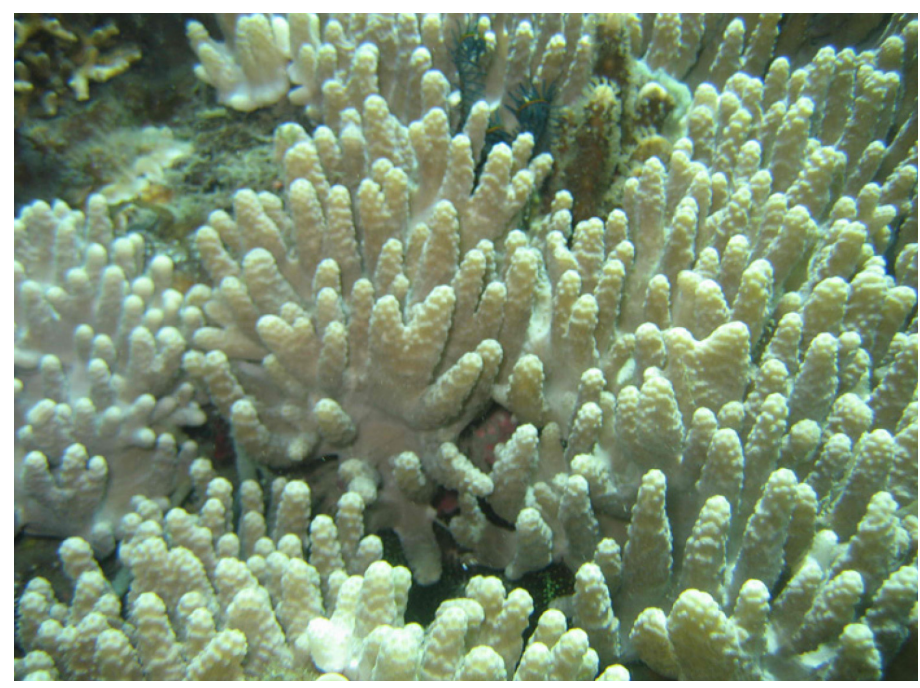

Figure 2. Structure of Paralemnolide A (1).

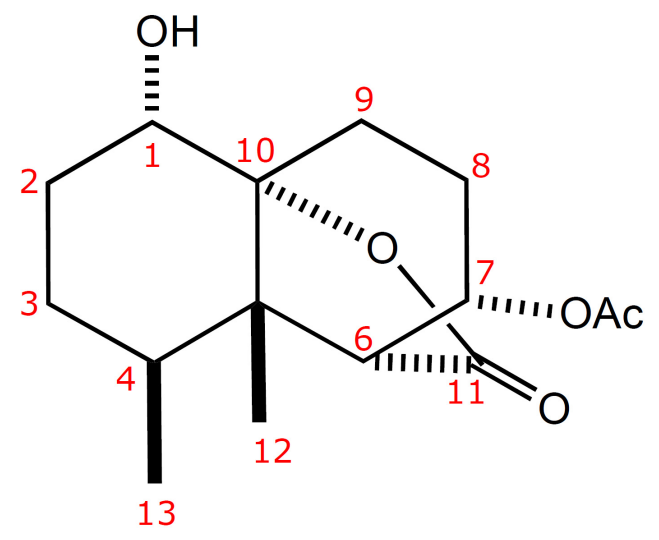

\section{Results and Discussion}

The acetone extract of $P$. thyrsoides was concentrated to a brown gum, which was partitioned between EtOAc and $\mathrm{H}_{2} \mathrm{O}$. The EtOAc-soluble residue $(20 \mathrm{~g})$ was subjected to a series of chromatographic separations to yield $\mathbf{1}$.

Paralemnolide A (1) was obtained as a colorless oil. The HRESIMS of 1 exhibited a $[\mathrm{M}+\mathrm{Na}]^{+}$ peak at $m / z$ 305.1367, consistent with the molecular formula of $\mathrm{C}_{15} \mathrm{H}_{22} \mathrm{O}_{5}$, implying five degrees of unsaturation. The ${ }^{13} \mathrm{C}$ NMR and DEPT spectra showed resonances for three methyls, four methylenes, four methines, and four quaternary carbons. The absorptions at $3447,1769,1742 \mathrm{~cm}^{-1}$ in its IR spectrum revealed the presence of hydroxyl and carbonyl groups. The ${ }^{1} \mathrm{H}$ and ${ }^{13} \mathrm{C}$ NMR spectra (Table 1) showed the presence of the following groups: (a) a secondary methyl $\left(\delta_{\mathrm{C}} 15.8 \mathrm{CH}_{3} ; \delta_{\mathrm{H}} 0.85 \mathrm{~d}, J=6.8 \mathrm{~Hz}\right)$, (b) a tertiary methyl $\left(\delta_{\mathrm{C}} 10.4 \mathrm{CH}_{3} ; \delta_{\mathrm{H}} 1.03 \mathrm{~s}\right)$, (c) two oxygenated methines $\left(\delta_{\mathrm{C}} 69.8 \mathrm{CH} ; \delta_{\mathrm{H}} 3.46 \mathrm{dd}\right.$, $J=11.6,5.2 \mathrm{~Hz}$ and $\delta_{\mathrm{C}} 66.7 \mathrm{CH} ; \delta_{\mathrm{H}} 5.17 \mathrm{ddd}, J=10.8,6.8,2.4 \mathrm{~Hz}$ ), and (d) an acetyl group $\left(\delta_{\mathrm{C}} 170.6 \mathrm{C}, 21.2 \mathrm{CH}_{3} ; \delta_{\mathrm{H}} 2.09 \mathrm{~s}\right)$. 
Table 1. ${ }^{1} \mathrm{H}$ and ${ }^{13} \mathrm{C}$ NMR Spectroscopic Data of $\mathbf{1}^{\mathrm{a}}$.

\begin{tabular}{|c|c|c|c|}
\hline $\mathrm{C} / \mathrm{H}$ & ${ }^{13} \mathrm{C}$ & & ${ }^{1} \mathbf{H}$ \\
\hline 1 & 69.8 & $\mathrm{CH}^{\mathrm{b}}$ & $3.46 \mathrm{dd}(11.6,5.2)^{\mathrm{c}}$ \\
\hline $2 \alpha$ & 30.5 & $\mathrm{CH}_{2}$ & $1.63 \mathrm{~m}$ \\
\hline $2 \beta$ & & & $1.95 \mathrm{~m}$ \\
\hline $3 \alpha$ & 27.8 & $\mathrm{CH}_{2}$ & $1.59 \mathrm{~m}$ \\
\hline $3 \beta$ & & & $1.35 \mathrm{~m}$ \\
\hline 4 & 35.0 & $\mathrm{CH}$ & $1.59 \mathrm{~m}$ \\
\hline 5 & 47.9 & $\mathrm{qC}$ & \\
\hline 6 & 53.3 & $\mathrm{CH}$ & $2.70 \mathrm{~d}(2.4)$ \\
\hline 7 & 66.7 & $\mathrm{CH}$ & 5.17 ddd $(10.8,6.8,2.4)$ \\
\hline $8 \alpha$ & 24.2 & $\mathrm{CH}_{2}$ & $1.63 \mathrm{~m}$ \\
\hline $8 \beta$ & & & $2.24 \mathrm{~m}$ \\
\hline $9 \alpha$ & 25.3 & $\mathrm{CH}_{2}$ & $2.57 \mathrm{~m}$ \\
\hline $9 \beta$ & & & $1.73 \mathrm{~m}$ \\
\hline 10 & 89.2 & $\mathrm{qC}$ & \\
\hline 11 & 175.0 & $\mathrm{qC}$ & \\
\hline 12 & 10.4 & $\mathrm{CH}_{3}$ & $1.03 \mathrm{~s}$ \\
\hline 13 & 15.8 & $\mathrm{CH}_{3}$ & $0.85 \mathrm{~d}(6.8)$ \\
\hline \multirow[t]{2}{*}{ OAc } & 170.6 & $\mathrm{qC}$ & \\
\hline & 21.2 & $\mathrm{CH}_{3}$ & $2.09 \mathrm{~s}$ \\
\hline
\end{tabular}

${ }^{\text {a }}$ Spectra were measured in $\mathrm{CDCl}_{3}\left({ }^{1} \mathrm{H}, 400 \mathrm{MHz}\right.$ and $\left.{ }^{13} \mathrm{C}, 100 \mathrm{MHz}\right) ;{ }^{\mathrm{b}}$ Multiplicities are deduced by HSQC and DEPT experiments; ${ }^{\mathrm{c}} J$ values (in $\mathrm{Hz}$ ) are in parentheses.

By interpretation of ${ }^{1} \mathrm{H}-{ }^{1} \mathrm{H}$ COSY correlations (Figure 3), it was possible to establish two partial structures of consecutive proton systems extending from $\mathrm{H}-1$ to Me-13 through $\mathrm{H}-2, \mathrm{H}-3$, and $\mathrm{H}-4$ as well as from $\mathrm{H}-6$ to $\mathrm{H}_{2}-9$ through $\mathrm{H}-7$ and $\mathrm{H}-8$. HMBC correlations of (a) $\mathrm{CH}_{3}-13$ to $\mathrm{C}-3, \mathrm{C}-4$, and C-5, (b) $\mathrm{CH}_{3}-12$ to C-4, C-5, C-6, and C-10, (c) H-6 and H-7 to the carbonyl C-11 atom, and (d) H-1, $\mathrm{H}-6$, and $\mathrm{H}-9$ to $\mathrm{C}-10$ connected the latter two spin systems concluding the planar structure of $\mathbf{1}$, as shown in Figure 3. The above functionalities revealed that paralemnolide A (1) possesses a novel bisnorsesquiterpene tricyclic skeleton.

Figure 3. Key ${ }^{1} \mathrm{H}_{-}{ }^{1} \mathrm{H} \operatorname{COSY}(-)$ and $\mathrm{HMBC}(\mathrm{H} \rightarrow \mathrm{C})$ correlations of $\mathbf{1}$.

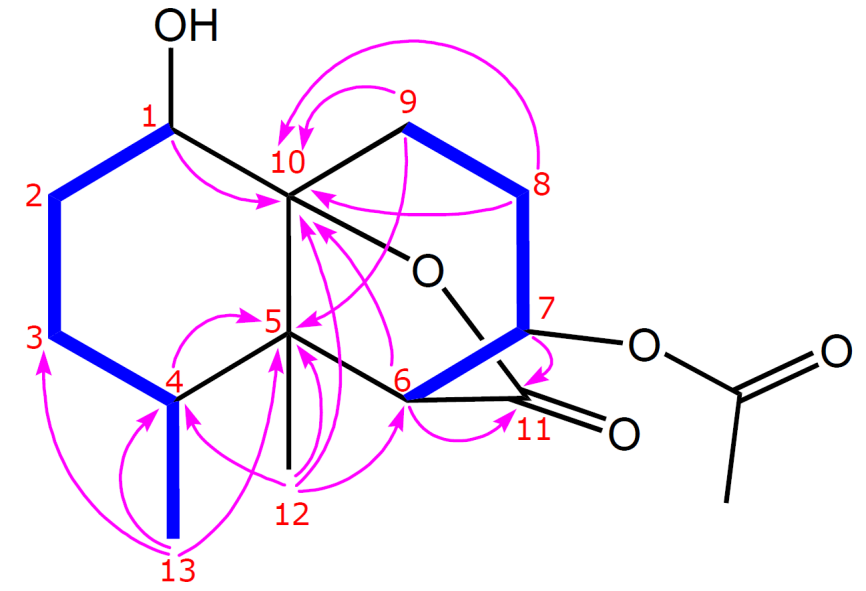


The relative configuration of $\mathbf{1}$ was deduced from a NOESY experiment. NOE correlations of $\mathrm{H}-1 / \mathrm{H}_{3}-12, \mathrm{H}-6 / \mathrm{H}_{3}-12, \mathrm{H}-6 / \mathrm{H}_{3}-13$, and $\mathrm{H}-7 / \mathrm{H}_{3}-12$ suggested all to be on the $\beta$-side of the molecule (Figure 4).The absolute configuration of 1 was determined by application of the modified Mosher method [9]. Treatment of 1 with $(R)$-MTPA chloride and $(S)$-MTPA chloride afforded the $(S)$-MTPA ester (1a) and (R)-MTPA ester (1b), respectively. The difference in chemical shift values $\left(\delta_{S}-\delta_{R}\right)$ for the diastereomeric esters $\mathbf{1 a}$ and $\mathbf{1 b}$ was calculated in order to assign the absolute configuration at $\mathrm{C}-1$. Calculations for all of the relevant signals suggested the $1 S$ absolute configuration. Therefore, the $4 S, 5 S, 6 R, 7 S$, and $10 R$ absolute configuration was proposed for 1 on the basis of the $\Delta \delta$ results summarized in Figure 5.

Figure 4. Selected NOESY correlations of 1.

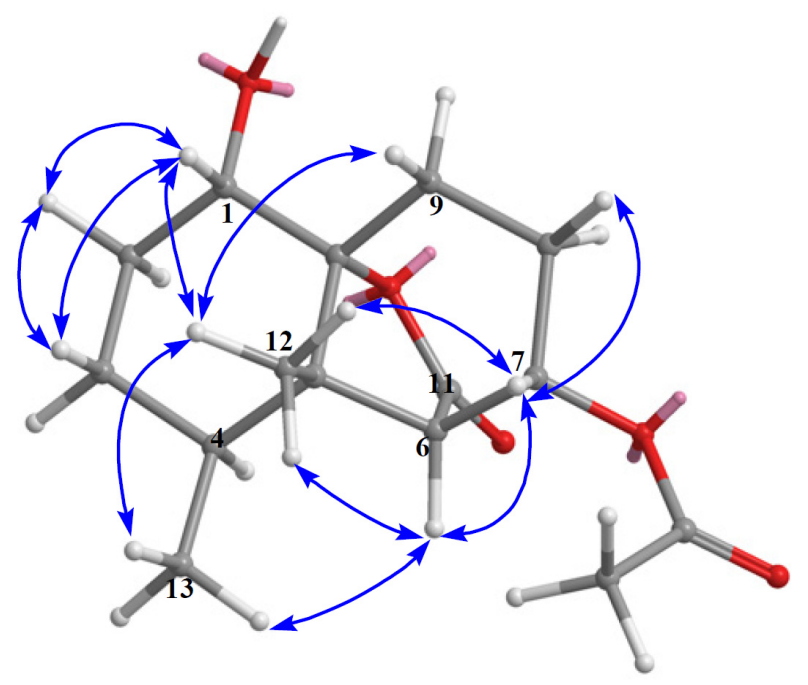

Figure 5. Absolute stereochemistry of 1: values $\left(\delta_{S}-\delta_{R}\right)$ in ppm for the two MTPA esters $\mathbf{1 a}$ and $\mathbf{1 b}$.

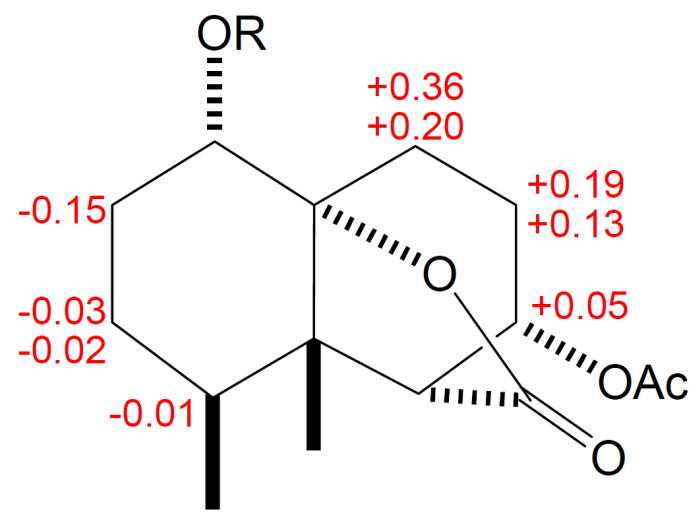

1a $\mathrm{R}=(S)-\mathrm{MTPA}$

1b $\mathrm{R}=(R)-\mathrm{MTPA}$

It is worthwhile to mention that the framework of 1 may be derived from 1(10)-aristolene through a sequence of oxidative cleavage, reduction, epoxidation, oxidative cleavage, and lactonization to result in the formation of paralemnolide A (1) as depicted in Scheme 1. 
Scheme 1. Possible Biogenetic Pathway for 1.

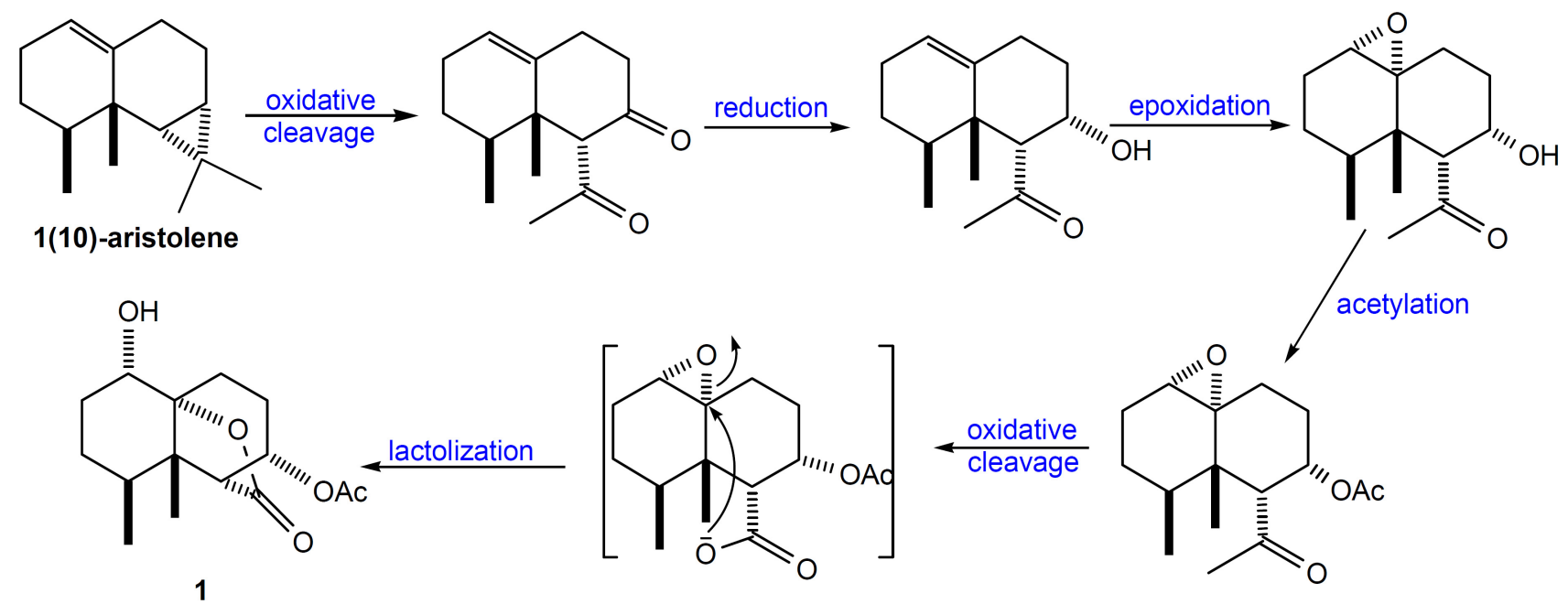

Paralemnolide A (1) was evaluated for cytotoxicity against P-388, A549, and HT-29 cancer cell lines. Metabolite 1 displayed moderate cytotoxicity against P-388, with an $\mathrm{ED}_{50}$ of $3.8 \mu \mathrm{g} / \mathrm{mL}$. With the exception of the above finding, the obtained negative result showed that $\mathbf{1}$ was not cytotoxic against A549, and HT-29 cancer cell lines $\left(\mathrm{ED}_{50}>50 \mu \mathrm{g} / \mathrm{mL}\right)$. The compound was also examined for antiviral activity against human cytomegalovirus (HCMV) using a human embryonic lung (HEL) cell line. Paralemnolide A (1) did not show anti-HCMV activity.

\section{Experimental Section}

\subsection{General Experimental Procedures}

Optical rotations were determined with a JASCO P1020 digital polarimeter. UV and IR spectra were obtained on JASCO V-650 and JASCO FT/IR-4100 spectrophotometers, respectively. NMR spectra were recorded on a Varian MR 400 NMR spectrometer at $400 \mathrm{MHz}$ for ${ }^{1} \mathrm{H}$ and $100 \mathrm{MHz}$ for ${ }^{13} \mathrm{C}$, respectively. ${ }^{1} \mathrm{H}$ NMR chemical shifts are expressed in $\delta(\mathrm{ppm})$ referring to the solvent peak $\delta_{\mathrm{H}}$ 7.27 for $\mathrm{CDCl}_{3}$, and coupling constants are expressed in $\mathrm{Hz} .{ }^{13} \mathrm{C}$ NMR chemical shifts are expressed in $\delta(\mathrm{ppm})$ referring to the solvent peak $\delta_{\mathrm{C}} 77.0$ for $\mathrm{CDCl}_{3}$. MS were recorded by a Bruker APEX II mass spectrometer. Silica gel 60 (Merck, Germany, 230-400 mesh) and LiChroprep RP-18 (Merck, 40-63 $\mu \mathrm{m}$ ) were used for column chromatography. Precoated silica gel plates (Merck, Kieselgel $60 \mathrm{~F}_{254}, 0.25 \mathrm{~mm}$ ) and precoated RP-18 $\mathrm{F}_{254 \mathrm{~s}}$ plates (Merck) were used for thin-layer chromatography (TLC) analysis. High-performance liquid chromatography (HPLC) was carried out using a Hitachi L-7100 pump equipped with a Hitachi L-7400 UV detector at $220 \mathrm{~nm}$ together with a semi-preparative reversed-phase column (Merck, Hibar LiChrospher RP-18e, $5 \mu \mathrm{m}, 250 \times 25 \mathrm{~mm}$ ).

\subsection{Biological Material}

The octocoral $P$. thyrsoides was collected by hand using scuba at the Sansiantai, Taitong County, Taiwan, in July 2008, at a depth of $6 \mathrm{~m}$. This soft coral was identified by Prof. Chang-Fong Dai, Institute of Oceanography, National Taiwan University. A voucher specimen (SST-07) was deposited in the Department of Marine Biotechnology and Resources, National Sun Yat-sen University. 


\subsection{Extraction and Isolation}

The frozen soft coral was chopped into small pieces and extracted with acetone in a percolator at room temperature. The acetone extract of $P$. thyrsoides was concentrated to a brown gum, which was partitioned with EtOAc and $\mathrm{H}_{2} \mathrm{O}$. The EtOAc-soluble residue $(20 \mathrm{~g})$ was subjected to Si $60 \mathrm{CC}$ using $n$-hexane-EtOAc mixtures of increasing polarity for elution. Fractions eluted by $n$-hexane-EtOAc $(2: 1)$ were further purified by RP-18 HPLC [eluted with $\mathrm{MeOH}-\mathrm{H}_{2} \mathrm{O}$ (1:1)] to yield 1 (2.2 mg).

Paralemnolide A (1): colorless, viscous oil; $[\alpha]_{\mathrm{D}}{ }^{25}-25$ (c 0.4, $\left.\mathrm{CHCl}_{3}\right)$; IR (neat) $v_{\max } 3447,3038$, 2964, 1769, 1456, 1379, $1239 \mathrm{~cm}^{-1}$; ${ }^{1} \mathrm{H}$ NMR and ${ }^{13} \mathrm{C}$ NMR data, see Table 1; HRESIMS $\mathrm{m} / z 305.1367$ $[\mathrm{M}+\mathrm{Na}]^{+}$(calcd. for $\mathrm{C}_{15} \mathrm{H}_{22} \mathrm{O}_{5} \mathrm{Na}, 305.1365$ ).

Preparation of Mosher's esters of $\mathbf{1}$. In separate NMR tubes, duplicate $(0.7 \mathrm{mg})$ samples of 1 were dissolved in $0.6 \mathrm{~mL}$ of pyridine- $d_{5}$ and allowed to react for $3 \mathrm{~h}$ at room temperature with $(R)$ - and $(S)$-MTPA chloride (one drop) to yield (S)-MTPA ester 1a and $(R)$-MTPA ester 1b, respectively. ${ }^{1} \mathrm{H}-\mathrm{NMR}$ (pyridine- $d_{5}, 400 \mathrm{MHz}$ ) of 1a: $\delta_{\mathrm{H}} 0.67(3 \mathrm{H}, \mathrm{d}, J=6.8 \mathrm{~Hz}, \mathrm{Me}-13), 0.99(3 \mathrm{H}, \mathrm{s}, \mathrm{Me}-12), 1.32$

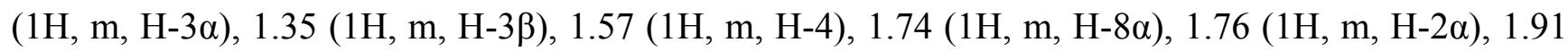

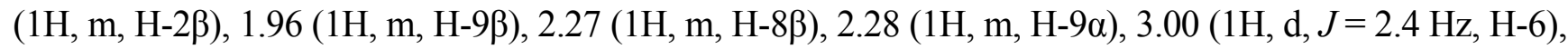
5.27 (1H, dd, $J=11.6,5.2 \mathrm{~Hz}, \mathrm{H}-1), 5.31$ (1H, ddd, $J=10.8,7.6,3.2 \mathrm{~Hz}, \mathrm{H}-7), 7.46-7.66$ (5H, m, Ph). ${ }^{1} \mathrm{H}-\mathrm{NMR}$ (pyridine- $d_{5}, 400 \mathrm{MHz}$ ) of $\mathbf{1 b}: \delta_{\mathrm{H}} 0.67(3 \mathrm{H}, \mathrm{d}, J=7.2 \mathrm{~Hz}, \mathrm{Me}-13), 0.97(3 \mathrm{H}, \mathrm{s}, \mathrm{Me}-12), 1.35$

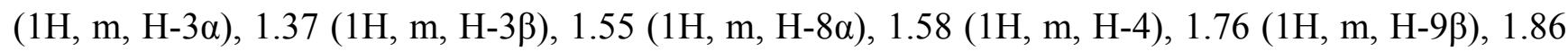

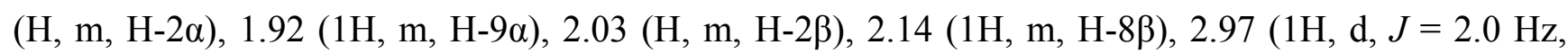
H-6), 5.23 (1H, dd, $J=11.6,4.80 \mathrm{~Hz}, \mathrm{H}-1), 5.26$ (1H, ddd, $J=10.8,6.4,3.2 \mathrm{~Hz}, \mathrm{H}-7), 7.45-7.65$ $(5 \mathrm{H}, \mathrm{m}, \mathrm{Ph})$.

\subsection{Cytotoxicity Assay}

Cytotoxicity was determined on P-388 (mouse lymphocytic leukemia), HT-29 (human colon adenocarcinoma), and A-549 (human lung epithelial carcinoma) tumor cells using a modification of the MTT colorimetric method according to a previously described procedure [10,11]. The provision of the P-388 cell line was supported by J.M. Pezzuto, formerly of the Department of Medicinal Chemistry and Pharmacognosy, University of Illinois at Chicago. HT-29 and A-549 cell lines were purchased from the American Type Culture Collection. To measure the cytotoxic activities of tested compounds, five concentrations with three replications were performed on each cell line. Mithramycin was used as a positive control.

\subsection{Anti-HCMV Assay}

To determine the effects of natural products upon HCMV cytopathic effect (CPE), confluent human embryonic lung (HEL) cells grown in 24-well plates were incubated for $1 \mathrm{~h}$ in the presence or absence of various concentrations of tested natural products with three replications. Ganciclovir was used as a positive control. Then, cells were infected with HCMV at an input of $1000 \mathrm{pfu}$ (plaque forming units) per well of a 24 -well dish. Antiviral activity was expressed as $\mathrm{IC}_{50}$ (50\% inhibitory concentration), or compound concentration required to reduce virus induced CPE by $50 \%$ after 7 days as compared 
with the untreated control. To monitor the cell growth upon treating with natural products, an MTT-colorimetric assay was employed [12].

\section{Conclusion}

The first investigation of soft coral $P$. thyrsoides collected at San-Hsian-Tai (Taitong County, Taiwan) has led to the isolation of an unprecedented bisnorsesquiterpene, paralemnolide A (1) exhibiting cytotoxicity against P-388 cell line with $\mathrm{ED}_{50}$ of $3.8 \mu \mathrm{g} / \mathrm{mL}$.

\section{Acknowledgments}

This research was financially supported by grants from the National Science Council (NSC99-2628-B-110-002-MY3) and Ministry of Education of Taiwan awarded to C.-Y.D.

\section{References}

1. Su, J.Y.; Zhong, Y.L.; Zeng, L.M. Two new sesquiterpenoids from the soft coral Paralemnalia thyrsoides. J. Nat. Prod. 1993, 56, 288-291.

2. Bowden, B.F.; Coll, J.C.; Mitchell, S.J. Studies of Australian soft corals. XIX. Two newsesquiterpenes with the nardosinane skeleton from a Paralemnalia species. Aust. J. Chem. 1980, 33, 885-890.

3. Izac, R.R.; Schneider, P.; Swain, M.; Fenical, W. New nor-sesquiterpenoids of apparent nardosinane origin from the pacific soft-coral Paralemnalia thyrsoides. Tetrahedron Lett. 1982, $23,817-820$.

4. Huang, H.-C.; Chao, C.-H.; Su, J.-H.; Hsu, C.-H.; Chen, S.-P.; Kuo, Y.-H.; Sheu, J.-H. Neolemnane-type sesquiterpenoids from a Formosan soft coral Paralemnalia thyrsoides. Chem. Pharm. Bull. 2007, 55, 876-880.

5. Wang, G.-H.; Huang, H.-C.; Su, J.-H.; Wu, Y.-C.; Sheu, J.-H. Paralemnolins J-P, new sesquiterpenoids from the soft coral Paralemnalia thyrsoides. Chem. Pharm. Bull. 2010, 58, 30-33.

6. Huang, H.-C.; Chao, C.-H.; Liao, J.-H.; Chiang, M.Y.; Dai, C.-F.; Wu, Y.-C.; Sheu, J.-H. A novel chlorinated norsesquiterpenoid and two related new metabolites from the soft coral Paralemnalia thyrsoides. Tetrahedron Lett. 2005, 46, 7711-7714.

7. Huang, H.-C.; Wen, Z.-H.; Chao, C.-H.; Ahmed, A.F.; Chiang, M.Y.; Kuo, Y.-H.; Hsu, C.-H.; Chen, S.-P; Sheu, J.-H. Novel sesquiterpenoids from the Formosan soft coral Paralemnalia thyrsoides. Tetrahedron Lett. 2006, 47, 8751-8755.

8. Daloze, D.; Braekman, J.C.; Georget, P.; Tursch, B. Chemical studies of marine invertebrates. XXII. Two novel sesquiterpenes from soft corals of the genera Lemnalia and Paralemnalia. Bull. Soc. Chim. Belg. 1977, 86, 47-54.

9. Ohtani, I.; Kusumi, T.; Kashman, Y.; Kakisawa, H.J. Am. Chem. Soc. 1991, 113, 4092-4096.

10. Hou, R.-S.; Duh, C.-Y.; Chiang, M.Y.; Lin, C.-N. Sinugibberol, a new cytotoxic cembranoid diterpene from the soft coral Sinularia gibberosa. J. Nat. Prod. 1995, 58, 1126-1130. 
11. Geran, R.I.; Greenberg, N.H.; MacDonald, M.M.; Schumacher, A.M.; Abbott, B.J. Protocols for screening chemical agents and natural products against animal tumors and other biological syatems. Cancer Chemother. Rep. 1972, 3, 1-91.

12. Stevens, M.; Balzarini, J.; Tabarrini, O.; Andrei, G.; Snoeck, R.; Cecchetti, V.; Fravolini, A.; de Clercq, E.; Pannecouque, C. Cell-dependent interference of a series of new 6-aminoquinolone derivatives with viral (HIV/CMV) transactivation. J. Antimicrob. Chemother. 2005, 56, 847-855.

Samples Availability: Not available.

(C) 2012 by the authors; licensee MDPI, Basel, Switzerland. This article is an open access article distributed under the terms and conditions of the Creative Commons Attribution license (http://creativecommons.org/licenses/by/3.0/). 